\title{
Climate engineering: A critical review of approaches to modify the global energy balance
}

\author{
J. Feichter ${ }^{1}$ and T. Leisner ${ }^{2}$ \\ 1 Max-Planck-Institut für Meteorologie, Hamburg, Germany \\ 2 Institut für Meteorologie und Klimaforschung, Forschungszentrum Karlsruhe, Germany
}

\begin{abstract}
Besides mitigation and adaptation, climate engineering, i.e. the large scale manipulation of the climate system has recently been promoted as a third strategy to combat the unwanted consequences of anthropogenic climate change. In this contribution, we address three climate engineering schemes that have been proposed. One scheme attempts to reduce the incoming solar radiation far outside the atmosphere, the other two increase the earth albedo either by introducing aerosols into the stratosphere or by modifying clouds in the lower marine atmosphere. While all three schemes face severe engineering challenges, they are in principle able to bring the global energy budget back toward the preindustrial value. However, this only holds for the global average, while unintentional regional climate response must be expected. The regional response is hardly predictable, and it is even rather difficult to detect in view of climatic variability. On the other hand, climate engineering would have severe ecological, societal, legal and political implications. We conclude that none of the schemes offers itself as remedy for climate change, but argue that dedicated research on their potential and consequences is advisable.
\end{abstract}

\section{Introduction}

Controlling weather and climate always has been a dream of mankind but such ability was traditionally attributed to deities. Dreams to do so rose beyond the realm of magic only with the advent of nuclear power. Early scientific ideas tracing back into the 1940 were intimately related not only to weather modification, but also to geoforming, i.e. creating a world which is more suitable for the economic and military needs of ones nation. Two ideas worth mentioning here are the diversion of the Siberian rivers to irrigate central Asia [1] and the deliberate melting of the arctic ice sheet by steering warm Atlantic water into the Arctic Sea with the help of a gigantic dam that should be erected across the Bering strait [2]. Geoengineering in the more narrow sense of climate control got conceptual impetus by E. Teller, who considered technological options of preventing the earth to enter a new ice age [3]. Early attempts of geoforming resulted in ecological and ultimately economical disaster, the conversion of the Aral Sea into a desert being the most prominent example. Moreover, for many geoscientists the field was contaminated by its close proximity to military exploitation. This attitude slowly began to change, when it became more and more clear that mankind by its sheer number and activity has started to change the energy budget of the atmosphere, and to modify other vital compartments of the earth. Nobel laureate Paul Crutzen coined the phrase "anthropocene" for the dawning age of human domination of the geosphere [4]. He promoted the geoengineering discussion in 2006, by reasoning that deliberate modification of the climate might become the ultima ratio if all mitigation efforts to contain climate change failed [5]. Since then, the number of scientific papers on climate engineering has risen significantly. In this contribution, we will first give an 


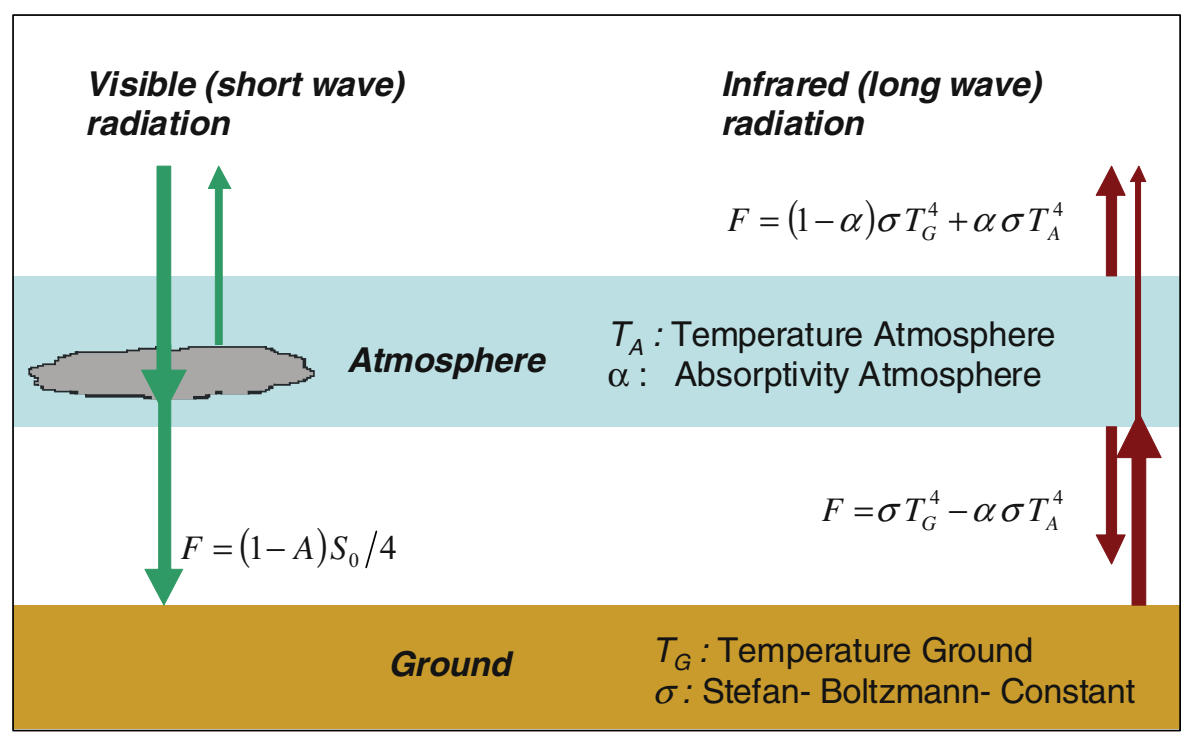

Fig. 1. Simplified shortwave (green) and and longwave (red) atmospheric radiation budget.

introduction into the physical basis of climate engineering. We will then review some of the presently most promising suggestions to control global warming which involve modifications of stratospheric and tropospheric aerosol and will touch the feasibility and possible side effects of such measures. Obviously, climate engineering will not be an issue of physical sciences alone, but has strong socio-economic and political implications, which will be mentioned only briefly in the concluding part.

\section{The energy budget of the atmosphere}

The incident solar radiation at top of the atmosphere is called the "solar constant" $\mathrm{S}_{0}$ and is measured by satellites to be roughly $1368 \mathrm{~W} / \mathrm{m}^{2}$. It has to be divided by four to get the time- and space averaged radiative energy input per square-meter of the earth surface which amounts to $342 \mathrm{~W} / \mathrm{m}^{2}$. Shortwave radiation from the sun undergoes various processes as it passes through the atmosphere. Two percent are absorbed in the stratosphere by ozone, $17 \%$ in the troposphere by aerosols and clouds, and 51\% are absorbed by the Earth's surface. $30 \%$ of solar radiation is returned back to the space by scattering and reflection. This $30 \%$, called albedo (A), is a key climate variable as it, combined with the insolation $\mathrm{S}_{0}$, determines the radiative energy input to the planet. The remaining $70 \%$ of the incoming solar radiation is absorbed by the Earth-atmosphere system where it is converted to sensible and latent heat and eventually, in an equilibrium situation, is returned as long-wave radiation. The long wave radiation flux directed from the surface into the atmosphere will be absorbed to some percentage $\alpha$ by water vapor and other greenhouse gases in the atmosphere. These absorbers again emit infrared radiation into space and back to the surface according to the Stefan-Boltzmann law. The long wave opaqueness of the atmosphere leads to an enhanced earth surface temperature as compared to the situation with a transparent atmosphere. From a simple conceptual model, as it is depicted in Fig. 1, a quantitative estimate for the earth surface temperature can be deduced as a function of the solar constant $\mathrm{S}_{0}$, the albedo $\mathrm{A}$ and the long wave absorptivity $\alpha$ of the atmosphere. By equating the short wave energy flux $(\mathrm{F})$ onto the ground both to the long wave budget at ground level and at the top of the atmosphere, the temperature of the atmosphere $\mathrm{T}_{\mathrm{A}}$ can be eliminated and $\mathrm{T}_{\mathrm{G}}$, the equilibrium ground temperature is calculated to be:

$$
T_{G}=\sqrt[4]{\frac{S_{0}(1-A)}{2 \sigma(2-\alpha)}} .
$$


As it is evident from Eq. 1, the ground temperature is increasing as the solar constant or the long wave absorptivity increases or the albedo decreases. This calculation is obviously oversimplified and neglects important physical and dynamical properties of the atmosphere, most prominently the vertical temperature gradient, the wavelength-dependence of $\alpha$ and the flux of latent heat by water vapor. Nevertheless it gives a remarkably good estimate of the ground temperature for realistic values of $\alpha \sim 0.8$.

\section{Classification of climate engineering schemes}

Moreover, and more important for this treatment, the simple model discussed above illustrates that any climate modification has to rely either on modification of $\mathrm{S}_{0}, \mathrm{~A}$, or $\alpha$. This allows for a convenient taxonomy of climate engineering schemes which we will adopt here. Table 1 gives an overview over several proposed climate modification schemes and how they fit into the proposed classification scheme. These examples are not complete and not necessarily selected because of their practical relevance. They rather illustrate the span of the proposed schemes.

Table 1. Taxonomy of some proposed climate engineering schemes.

\begin{tabular}{|l|l|l|}
\hline $\begin{array}{l}\text { A: Changing the solar } \\
\text { constant } \mathrm{S}_{0}\end{array}$ & $\begin{array}{l}\text { B: Increasing the planetary } \\
\text { albedo A }\end{array}$ & $\begin{array}{l}\text { C: Reducing the } \\
\text { atmospheric absorptivity } \alpha\end{array}$ \\
\hline $\begin{array}{l}\text { Scatterers or absorbers in } \\
\text { Lagrangian points between } \\
\text { sun and earth or in earth orbits }\end{array}$ & $\begin{array}{l}\text { Artificial scatterers (aerosols) } \\
\text { in the stratosphere or } \\
\text { troposphere }\end{array}$ & $\begin{array}{l}\text { Biological and geochemical } \\
\mathrm{CO}_{2} \text { sequestration by } \\
\text { fertilization of the oceans }\end{array}$ \\
\hline $\begin{array}{l}\text { Changing the orbital } \\
\text { parameters of the earth }\end{array}$ & $\begin{array}{l}\text { Changing the albedo of land or } \\
\text { sea-surface }\end{array}$ & $\begin{array}{l}\text { Technical extraction of } \mathrm{CO}_{2} \text { or } \\
\text { other greenhouse gases from air }\end{array}$ \\
\hline & $\begin{array}{l}\text { Changing cloud albedo by } \\
\text { aerosol modification }\end{array}$ & $\begin{array}{l}\mathrm{CO}_{2} \text {-uptake by terrestrial } \\
\text { ecosystems }\end{array}$ \\
\hline
\end{tabular}

The schemes A and B bear some similarity as they both address the short wave energy flux, whereas the schemes in $\mathrm{C}$ do more directly counteract the anthropogenic influence on the radiation budget and therefore are not always considered climate engineering but may be regarded a repair action for the anthropogenic release of greenhouse gases. In this contribution, we will focus on the former group and here mainly on group B, as the schemes proposed here seem technically the most feasible. It will become evident below, that theses schemes can be thought of as aerosol modification schemes, their point of action is the artificial modification of the atmospheric aerosol system. We will therefore give a brief introduction to atmospheric aerosols and their impact on the atmospheric energy budget.

\section{Aerosols and their role in the climate system}

Aerosols cover the particulate matter in the atmosphere. They span a large size range from about $10 \mathrm{~nm}$ to $20 \mu \mathrm{m}$ in diameter. Smaller particles are too short lived with respect to coagulation or growth by condensation and larger particles settle quickly by gravitation. With respect to their origin, aerosols are usually classified as primary or dispersion mode particles, as secondary or nucleation mode particles or as accumulation mode particles. Primary particles are generated from dispersion processes directly from the surface and are usually found in a micrometer size range. Dispersion processes active on the surface include sea spray, smoke from fires and other combustion processes, or dust dispersion by wind. In contrast, nucleation mode particles are generated within the atmosphere by nucleation of low volatility components, which were generated usually by photochemistry. Initially, these particles are formed in a size range around several nanometers but they tend to grow quickly to about $10 \mathrm{~nm}-20 \mathrm{~nm}$ by further condensation and coagulation. Prime examples of nucleation mode particles are sulfuric acid droplets or organic aerosols from oxidized biogenic precursor gases. Accumulation mode particles are created from nucleation mode particles by further growth by coagulation, condensation 


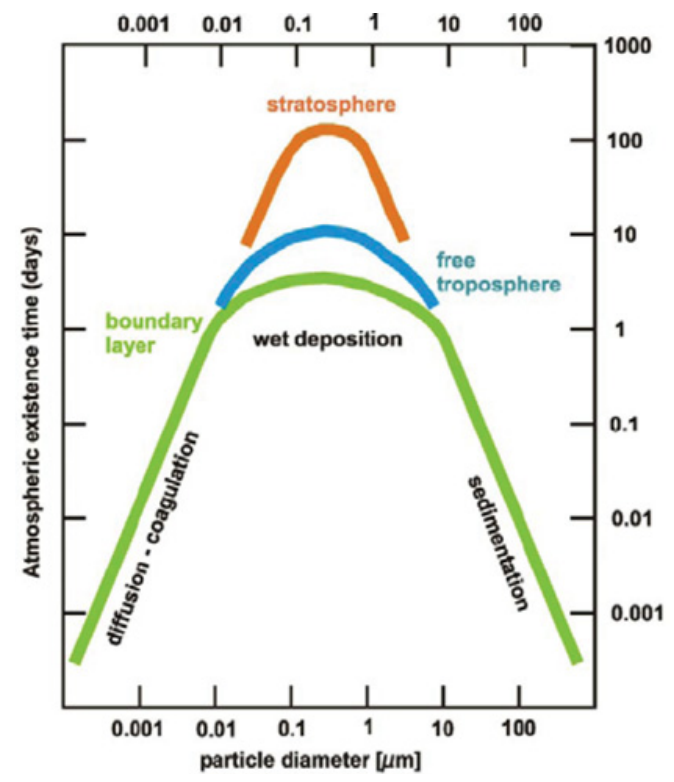

Fig. 2. Size dependence of the lifetime of atmospheric aerosol particles (adapted from Jaenicke [6]).

or cloud processes. They are usually of complex chemical composition and are found in the size range around several hundred nanometers. Particles in this size range accumulate in the atmosphere as they have the longest lifetime.

As evident from Fig. 2, the average lifetime of accumulation mode particles ranges from several days for particles close to the surface up to one year for stratospheric particles. The main removal process for these particles is wet deposition by precipitation. Smaller particles are removed efficiently from their size class by growth into larger accumulation mode particles by condensation, coagulation or cloud processes. Larger primary aerosols settle more rapidly by deposition under the influence of gravity.

The aerosol particle number density in the atmosphere is highly variable and ranges from more than $10^{6} \mathrm{~cm}^{-3}$ in urban environments over about $10^{3} \mathrm{~cm}^{-3}$ in pristine rural air down to $10^{2} \mathrm{~cm}^{-3}$ over the oceans. Nucleation mode particles usually dominate by far in number, but any mode may govern the aerosol mass density distribution, depending on the history of the air parcel. Despite of their seemingly large number, aerosol particles are true trace constituents of the atmosphere, their mass fraction typically being below one part per billion and thereby much below that of any important gaseous climate agent. Nevertheless they may have a profound influence on our climate. This perception is not at all new, only 20 years after Aitken discovered the importance of aerosols as condensation nuclei, Alfred R. Wallace noted in 1898 [7]:

But in all densely-populated countries there is an enormous artificial production of dust... This superabundance of dust .... must almost certainly produce some effect on our climate; and the particular effect it seems calculated to produce is the increase of cloud and fog, but not necessarily any increase of rain.

A modern perspective on the importance of aerosols on climate is reflected in Fig. 3 taken from the Fourth Assessment Report of the Intergovernmental Panel on Climate Change [8].

The figure shows that the main anthropogenic activities that produce a net cooling effect on our climate are related to aerosols. They are subdivided into "direct aerosol effect" which describes the direct enhancement of the atmospheric albedo by scattering of light on aerosol particles and "indirect or cloud albedo effect", which summarizes the effects aerosols can have on the albedo and lifetime of clouds. For both effects, the error bars are large and the level of scientific understanding is reported to range from medium to low.

Given the low mass mixing ratio of aerosol particles and their strong cooling potential, it becomes evident that both direct and indirect aerosol effect are prime candidates for climate 


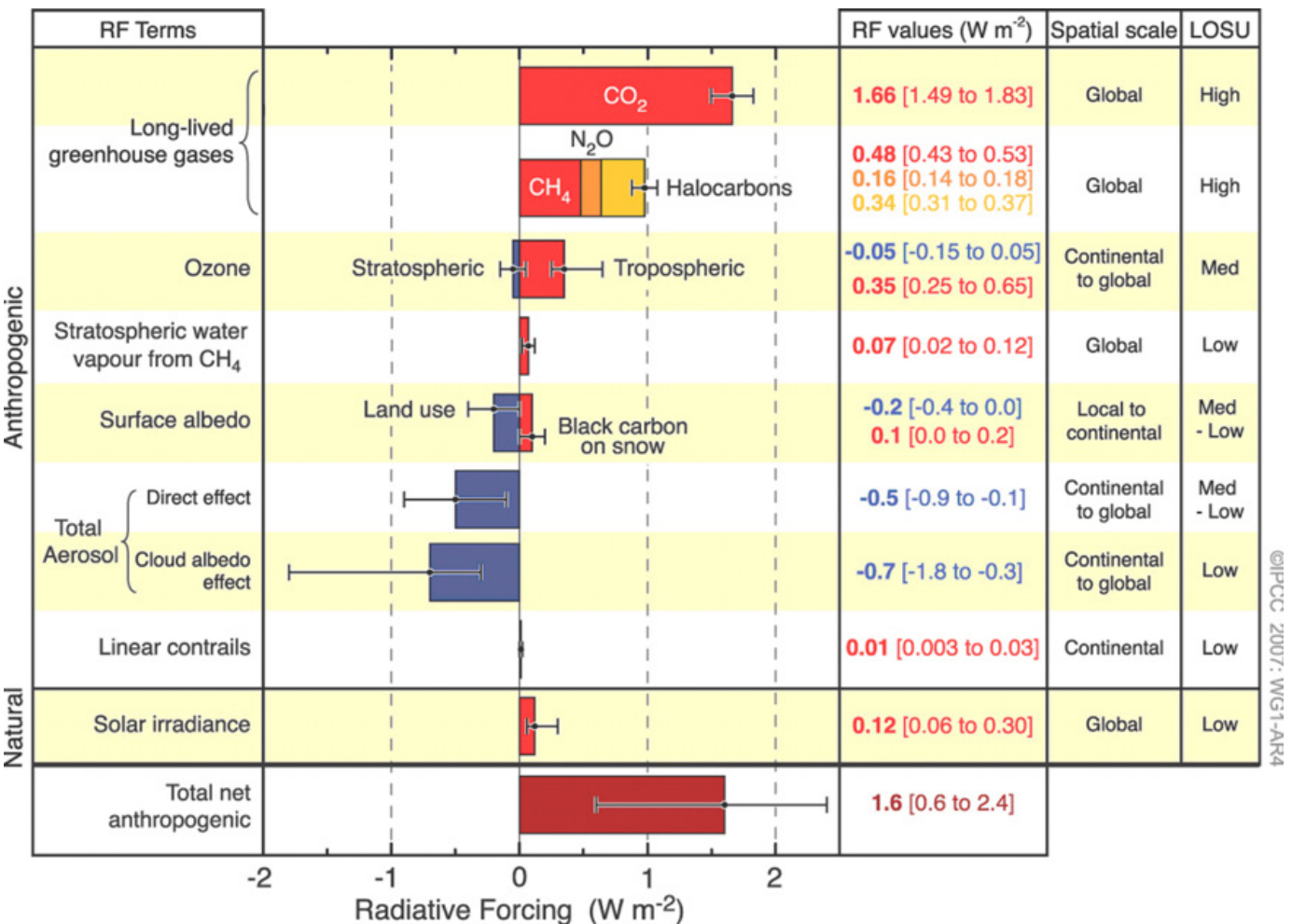

Fig. 3. Global average radiative forcing $(\mathrm{RF})$ estimates and ranges in 2005 for anthropogenic carbon dioxide $\left(\mathrm{CO}_{2}\right.$, methane $\left(\mathrm{CH}_{4}\right)$, nitrous oxide $\left(\mathrm{N}_{2} \mathrm{O}\right)$ and other important agents and mechanisms, together with the typical geographical extent (spatial scale) of the forcing and the assessed level of scientific understanding (LOSU). Figure SPM.2 p 4 in ref [8].

engineering concepts that aim on counteracting global warming. Below, a representative for each aerosol effect will be discussed in more detail.

\section{Model investigations of solar insolation reduction}

To understand the climate system, and the feedbacks between the subsystems, climatologists have relied upon complex Earth System Models (ESM). ESMs represent a mathematical representation of the physical laws and processes that govern our climate system. These numerical models are limited by our understanding of what drives the climate as well as how the earth's climate responds to a variety of external and internal radiative forcings. While measurements cannot answer "what-if" questions, numerical models are virtual laboratories of the Earth system used by geoscientists to investigate system response to a wide variety of different forcings. Thus, ESMs are the tools to answer questions like "Does a specific climate engineering technique work?" and "Are there perilous side effects?".

We will review model studies exploring three different methods of climate engineering: (1) placing a space sunshade at the Lagrange point, (2) injecting sulfur into the stratosphere, and (3) seeding marine clouds by sea salt aerosol particles.

\subsection{Sunshade climate engineering}

This technique reduces solar insolation at top of the atmosphere by the placement of reflective mirrors at the Lagrange point L1. This Lagrange point L1 is the location between the Earth 
and the sun (distance from the earth to L1 $\sim 1.5$ Mio km) where gravitational forces and the orbital motion balance each other.

The feasibility of this technique was explored by Angel [9] who concluded that the technique could be developed and the costs for deployment would amount some trillion dollars and would take about 25 years. Recently this technique has been investigated using a complex climate model [10]. According to this study, one has to reduce solar insolation by $4.2 \%$ to compensate for a quadrupling of pre-industrial carbon dioxide concentrations. Although a global mean surface temperature reduction comparable to pre-industrial values can be achieved, the regional surface temperature distribution between the pre-industrial and the "engineered" simulation shows marked differences. The reason is, that a percentage reduction in solar insolation leads to a much higher forcing in the tropics as at high latitudes. The forcing due to increasing carbon dioxide concentrations shows a similar behavior, but the latitudinal gradient is less steep [10]. The combined solar and $\mathrm{CO}_{2}$ forcing gives a negative forcing at the equator and a positive at the poles. Accordingly, the temperature response is positive at high latitudes (where GHG warming is highest) and negative over the tropical oceans (where GHG warming is lowest). But due to feedback processes the response is not linear to the forcing patterns. Besides spatial differences in temperature response Lunt et al. [10] report also a weaker seasonal cycle. As a consequence of the reduced solar insolation at ground, evaporation and subsequently global mean precipitation is reduced by $5 \%$. Lower precipitation is simulated particularly over the continents at mid- and low latitudes.

\subsection{Stratospheric sulfur dioxide injection}

Sulfur dioxide in the stratosphere oxidizes via the reaction with the hydroxyl radical to sulfuric acid. The life-time of sulfur dioxide in the stratosphere due to this chemical transformation is about one month. The sulfuric acid gas forms together with water-vapor sulfate particles. This process is called binary nucleation. The nucleation rate depends on the sulfate vapor pressure, the temperature and the relative humidity. In the presence of aerosols sulfuric acid gas may condense onto pre-existing aerosol surfaces. Thus, condensation and nucleation process competes for the sulfuric acid vapor with condensation the dominating process if sufficient aerosol particles are available. Once particles are formed (freshly nucleated sulfate particles are in the size range of few $\mathrm{nm}$ ) they grow by condensation and coagulation.

Whereas the e-folding residence time of sulfate aerosol in the troposphere is in the order of few days, because it is efficiently removed by precipitation, the residence time in the stratosphere is in the order of one to two years. The primary sink of stratospheric aerosol is sedimentation due to gravitational settling. Larger particles settle faster than small ones and thus have a shorter residence time in the stratosphere. On the whole, we find that the aerosol size distribution, number concentration and residence time depends on the amount and concentration of sulfuric acid gas, which is controlled by the amount of sulfur dioxide injected, the dilution by transport and the hydroxyl radical concentration. The aerosol properties evolve depending on background aerosol, the ambient humidity and the temperature. For instance, Pinto et al. [11] report that at high volcanic eruption rates, aerosols tend to make larger particles, not greater number concentrations, because larger mass injections enhance the growth of the particles by condensation and coagulation. These larger particles settle faster. Thus, this self-limiting effect may restrict the total number of particles in the stratosphere and limit the magnitude of the climate engineering effect.

Incident solar radiation excites electric charges in particles causing oscillatory motions. The excited electric charges reradiate energy in all directions (scattering) and convert a part into thermal energy (absorption) [12]. The desired effect - a cooling to compensate for greenhouse gas warming - arises from this property of aerosols to scatter solar radiation back to the space. Aerosol scattering and absorption depends on the refractive indices of the chemical compounds, the particle size and the wavelength of the incident light. Small sulfate particles scatter solar radiation back to the space. Large particles scatter less efficiently, and also absorb thermal radiation and thus exert an additional warming effect which partly compensates the cooling. During night and in winter time in polar latitudes larger particles have just a warming effect. 
To be most effective for the purpose of climate modification the sulfate aerosol should meet three conditions: (1) it should be small in order to keep sedimentation low, (2) it should have the size where the backscattering cross section per unit mass is at maximum, and (3) the width of the size distribution should be narrow to meet requirement (2) and to keep the coagulation rate low because coagulation is less efficient if all particles have about the same size (see Rasch et al. [13] for a more thorough discussion).

To achieve maximum cooling by the sulfur dioxide mass injected, one has only limited influence on the development of the aerosol population by varying the latitude and altitude of injection and the injection intervals (emit continuously small amounts or place few injections of high amounts). So far no studies have been performed exploring the full space of possibilities using complex climate models. Almost all studies prescribed the microphysical properties of the aerosol rather than to calculate the evolution of the microphysical properties of the aerosol population. Most simulations inject the sulfur dioxide in the lower stratosphere at tropical latitudes into the rising branch of the Brewer-Dobson circulation ${ }^{1}$ in order to achieve a longer residence time of the sulfur in the stratosphere. Sulfate mass formed in the stratosphere is concentrated in low and in high latitudes. In mid-latitudes and the subtropics sulfate concentrations are lower because downward transport into the troposphere takes place in these latitudes. Although the sulfate amount is higher in winter, the forcing is highest when solar insolation is at maximum. In summer radiative forcing is highest in polar regions, averaged over the year in the equatorial region [13]. The regional pattern of the temperature response due to sulfate injections is similar to that due to an increase of greenhouse gases with stronger cooling over the continents and at polar latitudes and less cooling over the oceans. In contrast to observations the model simulations does not exhibit a winter warming which was observed after tropical volcanic eruptions [14]. Rasch et al. [15] report model simulations where they injected continuously $2 \mathrm{Tg}^{2}$ sulfur per year as sulfur dioxide, calculated the oxidation of sulfur dioxide to sulfate and the spatio- temporal distribution of sulfate. If they assume larger particle sizes as characteristic for volcanic active periods the global warming due to doubling of $\mathrm{CO}_{2}$ is reduced from $2.1 \mathrm{~K}$ to $0.7 \mathrm{~K}$ and if small particle sizes are assumed as characteristic for volcanic quiet periods the warming is reversed to a cooling of $-0.8 \mathrm{~K}$. However, if we compare these model simulations to the Pinatubo eruption in the year 1991, we find significantly weaker effects. Estimates of the amount of sulfur injected by the Pinatubo eruption range between $6 \mathrm{Tg}$ and $13 \mathrm{Tg} \mathrm{S}$ [16]. The cooling observed a year after amounted to $0.5 \mathrm{~K}$.

Besides sulfur injections some other chemical species have been proposed for injection into the stratosphere. For instance the injection of soot particles as a consequence of a nuclear conflict has been studied in some "nuclear winter" scenarios. The soot layer absorbs solar radiation and becomes warmer creating rising motion. This process is called self-lofting and might enhance considerably the residence time of soot particles in the stratosphere. But the warming in the stratosphere affects chemistry and reduces ozone concentrations [17]. Teller et al. [3] proposed to use dielectric material of optimal size. Moreover, they proposed to inject different amounts into different latitude bands to achieve a fine tuning of the climate effect. But the assumption of a "quiet stratosphere" is not justified, because stratospheric trace substances are quite efficiently dispersed meridionally.

\subsection{Seeding marine clouds by sea salt particles}

Sea salt particles are generated by bubbles bursting at the surface of the ocean and by droplets being torn off of wave crests. Sub-micron sea salt particles are a major source of cloud condensation nuclei $(\mathrm{CCN})$ in remote marine areas and, thus, changes in sea salt concentration may impact the microphysical properties of marine low-level clouds. An increase in CCN enhances cloud droplet number concentrations (CDNC) and reduces, given the cloud water amount does not change, cloud droplet size. An increase in droplet concentration causes the droplet surface

\footnotetext{
1 The Brewer-Dobson circulation is a residual circulation which causes uplifting in the tropics and descent in polar regions.

${ }^{2}$ Tera $=10^{12}$.
} 
area to increase and with that the cloud albedo. Clouds with a higher albedo scatter more solar radiation back to the space and exert a cooling effect. Moreover, clouds consisting of smaller droplets form less likely precipitation drops and thus, have a longer life time. Both albedo and life-time effect exert a cooling. However, the presence of giant sea salt particles $(>5 \mu \mathrm{m}-$ $10 \mu \mathrm{m})$ can initiate the formation of precipitation, promotes cloud dissipation and thereby exert a warming. Because the albedo of marine low level clouds is much higher $(\sim 35 \%)$ than the albedo of the oceans $(\sim 9 \%)$, changes in marine cloud optical properties have a significant impact on the Earth's radiation budget. Low level clouds cover about $40 \%$ of the ocean's surface and exert a global mean negative radiative forcing of $-22 \mathrm{~W} / \mathrm{m}^{2}$.

Quaas et al. [18] derived from satellite retrievals a linear regression yielding the sensitivity of CDNC to a change in aerosol concentration. This sensitivity, a measure of the aerosol-cloud effect, is found to be virtually always positive, with larger sensitivities over the oceans. This regression was used to give a first guess estimate of the climatic impact of an increase in sea salt aerosol concentrations (pers. comm. Johannes Quaas). If we assume a uniform CDNC of marine low level clouds of 400 cloud droplets per $\mathrm{cm}^{-3}$ (characteristic CDNC over remote southern hemisphere oceans as derived from satellite data ranges between $40 \mathrm{~cm}^{-3}-67 \mathrm{~cm}^{-3}$ ) [19], the radiative forcing due to the increase in CDNC is calculated as $-2.9 \mathrm{~W} / \mathrm{m}^{2}$. Given the relationship between CDNC and aerosol optical depth ${ }^{3}$ (AOD) from satellite data we needed an increase of the AOD by one order of magnitude to obtain a uniform CDNC of $400 \mathrm{~cm}^{-3}$ over the world's oceans.

Assuming aerosol size distributions as observed in the marine boundary layer, an enhancement of the AOD by one order of magnitude does not seem feasible. However, Latham et al. [20] and Salter et al. [21] propose a technique to produce monodisperse sea salt aerosol particles of around $1 \mu \mathrm{m}$ dry aerosol size using 20-meter-high rotors aboard seagoing vessels to generate saltwater spray. The sea salt particles are then transported into the cloud layers (typically between $600 \mathrm{~m}$ and $1500 \mathrm{~m}$ altitude) by turbulence. Because sea salt is highly hygroscopic one can assume that all particles in this size range serve as CCN and form cloud droplets. In addition, the monosdispersity keeps the coagulation between the particles low and prevents formation of large particles. Technically, the sea-spray tool is carried by 300 ton ships powered by Flettner rotors [21]. The vessels will drag turbines resembling oversize propellers through the water to provide the means for generating electrical energy. Some will be used for rotor spin but most will be used to create spray by pumping $30 \ell / \mathrm{s}$ of filtered water through banks of filters and then to micro-nozzles with piezo-electric excitation to vary drop diameter. To compensate for a doubling of $\mathrm{CO}_{2}$ one needs a working fleet of about 1500 vessels. Each unmanned spray vessel will have a global positioning system, a list of required positions and satellite communications to follow suitable cloud fields migrating with the seasons [21].

\section{Is climate engineering feasible?}

Basically, the methods described here have the potential to cool our planet. However, all estimates are based on model studies using climate models which still differ by a factor of three in simulating the temperature response due to a doubling of $\mathrm{CO}_{2}$. Most of the studies have neglected key feedbacks between aerosol microphysics, chemistry and changes in meteorology. Moreover, assumptions have been made resulting in very optimistic estimates of the efficiency of the measures proposed. Thus, the effectiveness of the climate engineering method cannot be predicted with sufficient accuracy but has to be monitored if applied. However, the response to engineering measures occurs against a backdrop of internal and natural and anthropogenic externally forced climate variability. The presence of this climate variability means that the detection and attribution of climate engineering measures is a statistical "signal-in-noise" problem $[22]$. Detection is the process of demonstrating that an observed change is significantly different (in a statistical sense) than can be explained by natural internal variability. Attribution of observed climate change means to isolate causes and effects. Figure 4 shows the annual and

\footnotetext{
3 AOD is a measure of the extinction of solar radiation by aerosol scattering and absorption between the point of observation and the top of the atmosphere.
} 

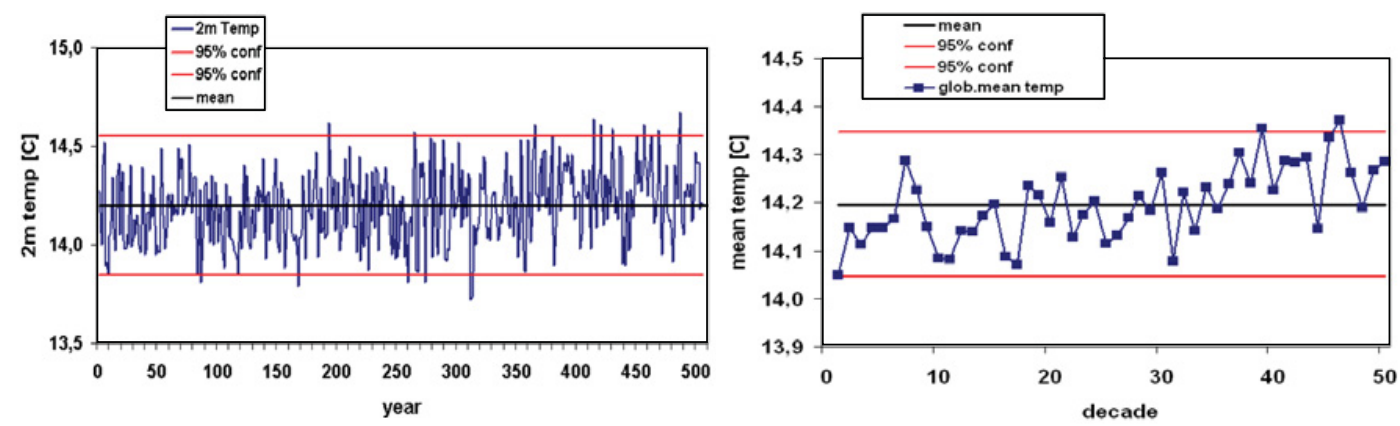

Fig. 4. Annual and global mean near-surface temperature calculated using a coupled ocean-atmosphere model applying constant radiative forcing representative for pre-industrial conditions (left graph). On the right-hand side 50 decadal averages are displayed calculated from the 500 year integration. The red line denotes the $95 \%$ confidence interval.

global mean surface temperature of a 500 year integration with constant pre-industrial forcing performed with the MPI coupled climate model [23]. Given a measure has been taken and the observed response is larger than the $95 \%$ percentile, we can be $95 \%$ certain that the difference is statistically significant; that means the climate engineering measure causes a significant change in temperature. Figure 4 shows that the longer the observation period resp. the application of climate engineering the smaller the temperature changes that are still detectable. The amplitude of the year-to-year internal variability is about $0.7 \mathrm{~K}$, but of the 50 year averages smaller than $0.3 \mathrm{~K}$.

In terms of investment costs the sun shade method is far the most expensive, the seaspray method the cheapest one. However, both methods have still to demonstrate their technical feasibility, whereas the method to inject sulfur into the stratosphere is technically less challenging.

The major advantages of the sea-spray method are that the measure can be switched off immediately, with conditions returning to normal within a few days, and a large part of the required energy is derived from the wind. In contrast, the about $10^{12}$ flyers launched within a 100,000-km-long cloud in the space, if applying the sun-shade method, can hardly be collected and removed.

\section{Are there side-effects?}

The concept of solar insolation reduction does not neutralize the greenhouse effect which acts on long-wave radiation and, thus, unintended regional climate response may occur. As demonstrated nicely by Govindasamy et al. [24], green house gas warming is effective at all latidues and throughout the year (Fig. 5a), while an enhanced short wave albedo cools preferentially where and when the sun shines most (Fig. 5b). This imbalance will be compensated to a large extend by a modified dynamics of atmospheric (and oceanic) energy transport.

Model simulations do show indeed that the temperature response pattern due to greenhouse gas forcing and due to solar insolation reduction is similar despite the imbalance in spatial and temporal distribution of the forcing. The response of the hydrological cycle however shows distinct differences. The hydrological sensitivity, defined as the change in global mean precipitation per one degree temperature change, is considerably higher for aerosol than for greenhouse gas forcing [23]. This is because the aerosol forcing primarily affects the surface radiation budget, whereas a major part of the greenhouse gas forcing is felt within the troposphere. The surface evaporates less if solar insolation is reduced and subsequently also precipitation rate declines accordingly.

Trenberth and Dai [25] analyzed observed precipitation following the eruption of Mount Pinatubo in June 1991 and found a substantial decrease in precipitation over land and a record decrease in runoff and river discharge into the oceans in the period October 1991 to September 

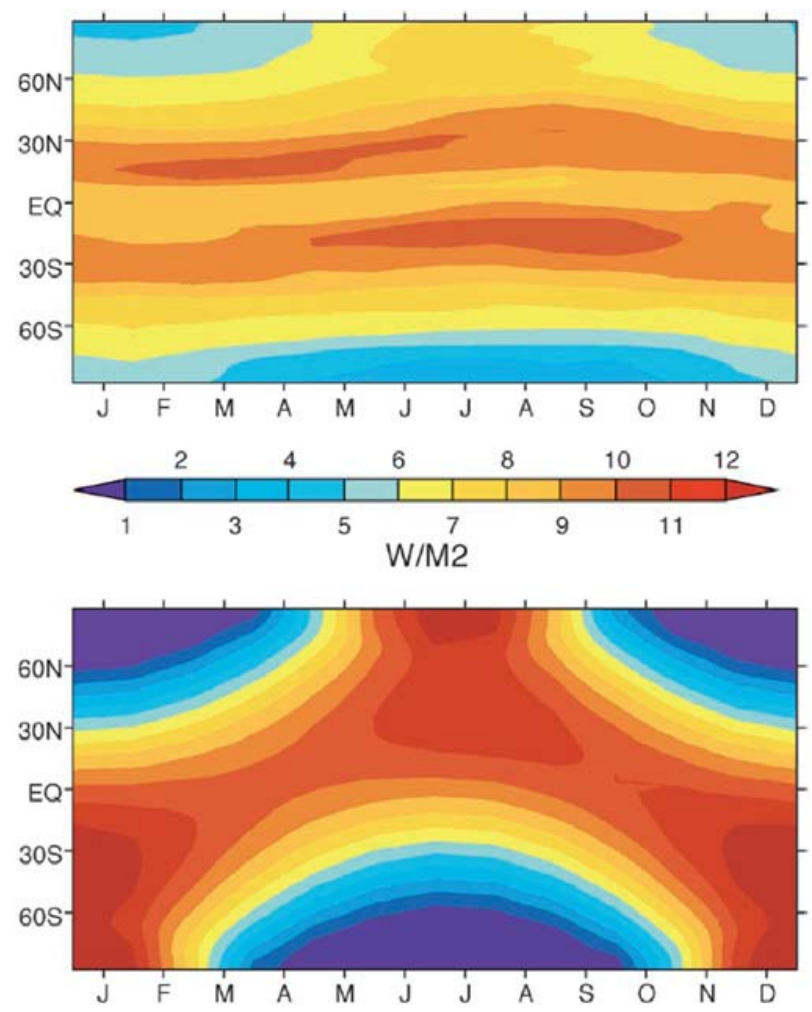

Fig. 5. Change in net long-wave radiative flux at the tropopause when $\mathrm{CO}_{2}$ is quadrupled (top panel) with respect to the Control case and the reduction in incoming solar radiation (bottom panel) needed to compensate this forcing. Both values $\left(\mathrm{W} / \mathrm{m}^{2}\right)$ are zonally averaged as a function of time of year. Change in solar radiation has a latitudinal and seasonal pattern markedly different from the radiative forcing of $\mathrm{CO}_{2}$. (From ref. [24], reprinted with permission.)

1992. They conclude that major adverse effects, including drought, could arise from solar insolation reduction.

Other side effects of solar radiation reduction are changes in the ozone chemistry of the stratosphere. Tilmes et al. [26] report that injection of sulfur large enough to compensate for surface warming caused by the doubling of atmospheric $\mathrm{CO}_{2}$ would strongly increase the extent of Arctic ozone depletion during the present century for cold winters and would cause a considerable delay, between 30 and 70 years, in the expected recovery of the Antarctic ozone hole.

\section{Beyond physical science}

If one or the other way of climate engineering will prove technologically feasible in the future, its shear existence will raise many legal, political and ethical questions which are at least difficult to resolve. We will point out here only some of the most apparent issues:

Climate Engineering has consequences which are not limited to the borders of countries or regions but exhibits global influence with different patterns of effects emerging in different regions. The implementation of engineering measures might therefore result in more beneficial climate change in some regions and in dangerous changes elsewhere. Moreover, the climate system reacts on changing forcing on a variety of timescales reaching from weeks to millennia. Slowly adapting parts of the climate system, as land surface changes or changes in ocean circulation might lead to unwanted side effects not until the climate system has changed irreversibly. 
Even within the most favourable scenarios, climate engineering would require global international cooperation and compensation which goes far beyond everything achieved hitherto and which has to be sustainable over centuries.

In a less ideal world, climate engineering strategies might be deployed by any technological and economical advanced nation from its territory without to arrange the measures with other nations. Such a unilateral strategy might affect climate and could impose costs elsewhere. Therefore an effective foreign policy and international conventions are needed. With ENMOD (Convention on the Prohibition of Military or any Other Hostile Use of Environmental Modification Techniques) an UN treaty already exists which prohibits military or other hostile use of environmental modification techniques. This treaty entered into force on October 1978 and was motivated by the anticipated progress in weather modification for military purposes. It might also restrict the implementation of climate engineering, if adverse effects at least in some regions are expected.

From the reasoning above it seems foolhardy to trust in a geoengineering solution to the climate change challenge. Nevertheless, we would like to argue for scientifically sound interdisciplinary research into all aspects of climate engineering well before the increasing toll from climate change pressures the decision makers to embark on a dubious and risky strategy. In the future, the private sector could emerge as a potent force pushing for deployment and driving the direction of climate engineering [27]. Therefore it seems highly advisable to encourage freely accessible interdisciplinary research that assesses the effectiveness, side effects and risks involved in climate engineering, before facts are accomplished.

\section{References}

1. H.H. Lamb, Climate engineering schemes to meet a climatic emergency, Earth Sci. Rev. 7, 87-95 (1971)

2. P.M. Borisov, Can we Control the Arctic Climate?, Bull. Atomic Scient. 43-48 (1969)

3. E. Teller, L. Wood, R. Hyde, Global Warming and Ice Ages: I. Prospects For Physics-Based Modulation of Global Change, 22nd International Seminar on Planetary Emergencies, Erice (Sicily), Italy, August 20-23, online available as reprint UCRL-JC-148012 by LLNL (1997)

4. P.J. Crutzen, Geology of mankind, Nature 415, 23 (2002)

5. P.J. Crutzen, Albedo Enhancements by Stratospheric Sulfur Injections: A Contribution to Resolve a Policy Dilemma?, Climatic Change 77, 211-219 (2006)

6. R. Jaenicke, Aerosol Physics and Chemistry. In: Landolt-Börnstein Numerical Data and Functional Relationships in Science and Technology New Series Group V: Geophysics and Space Research Volume 4 Meteorology Subvolume b, edited by G. Fischer, Physical and Chemical Properties of the Air (2007), pp. 391-457

7. A.R. Wallace, The Wonderful Century, Chapter IX: The Importance of Dust: A Source of Beauty and Essential to Life (Dodd, Mead And Company, 1899), p. 726 online available under: http://www.archive.org/details/wonderfulcentury028485mbp

8. IPCC, 2007: Summary for Policymakers, in: Climate Change 2007: The Physical Science Basis. Contribution of Working Group I to the Fourth Assessment Report of the Intergovernmental Panel on Climate Change Solomon, S., D. Qin, M. Manning, Z. Chen, M. Marquis, K.B. Averyt, M. Tignor and H.L. Miller (eds.) (Cambridge University Press, Cambridge, UK and New York, NY, USA, 2007)

9. R. Angel, Feasibility of cooling the Earth with a cloud of small spacecraft near the inner Lagrange point (L1), PNAS 103, 46 (2006)

10. D.J. Lunt, A. Ridgwell, P.J. Valdes, A. Seale, Sunshade World: A fully coupled GCM evaluation of the climatic impacts of geoengineering, Geophys. Res. Lett. 35, L12710 (2008)

11. J.R. Pinto, R. Turco, O. Toon, Self-limiting Physical and Chemical Effects in Volcanic Eruption Clouds, J. Geophys. Res. 94(D8), 11165 (1989)

12. J.H. Seinfeld, S.N. Pandis, Atmospheric Chemistry and Physics (John Wiley \& Sons, 1998)

13. P.J. Rasch, S. Tilmes, R.P. Turco, A. Robock, L. Oman, C.-C. Chen, G.L. Stenchikov, R.R. Garcia, An overview of geoengineering of climate using stratospheric sulphate aerosols, Philosoph. Transaction A 366, 1882 (2008)

14. A. Robock, L. Oman, G.L. Stenchikov, Regional climate responses to geoengineering with tropical and Arctic $\mathrm{SO}_{2}$ injections, J. Geophys. Res. 113, D16101 (2008) 
15. P.J. Rasch, P.J. Crutzen, D.B. Coleman, Exploring the geoengineering of climate using stratospheric sulfate aerosols: The role of particle size, Geophys. Res. Lett. 35, L02809 (2008)

16. A.J. Krueger, L.S. Walter, P.K. Bhartia, C.C. Schnetzler, N.A. Krotkov, I. Sprod, G.J.S. Bluths, J. Volcanic sulfur-dioxide measurements from the total ozone mapping intruments, Geophys. Res. 100, 14057 (1995)

17. M.J. Mills, O.B. Toon, R.P. Turco, D.E. Kinnison, R.R. Garcia, Massive global ozone loss predicted following regional nuclear conflict, Proc. Natl. Acad. Sci. U.S. 105, 5307 (2008)

18. J. Quaas, O. Boucher, N. Bellouin, S. Kinne, Satellite-based estimate of the direct and indirect aerosol climate forcing, J. Geophys. Res. 113, D05204 (2008)

19. R. Bennartz, Harshvardhan, Global assessment of marine boundary layer cloud droplet number concentration from satellite, J. Geophys. Res. 112, D02201 (2007)

20. J. Latham, P. Rasch, C.-C. Chen, L. Kettles, A. Gadian, A. Gettelman, H. Morrison, K. Bower, T. Choularton, Global temperature stabilization via controlled albedo enhancement of low-level maritime clouds, Phil. Trans. R. Soc. A 366, 3969 (2008)

21. S. Salter, G. Sortino, J. Latham, Sea-going hardware for the cloud albedo method of reversing global warming, Phil. Trans. R. Soc. A 366, 3989 (2008)

22. IPCC, 2001: Climate Change 2001: The Scientific Basis. Contribution of Working Group I to the Third Assessment Report of the Intergovernmental Panel on Climate Change, edited by Houghton, J.T., Y. Ding, D.J. Griggs, M. Noguer, P.J. van der Linden, X. Dai, K. Maskell, C.A. Johnson (Cambridge University Press, Cambridge, UK and New York, NY, USA, 2001)

23. B. Liepert, J. Feichter, U. Lohmann, E. Roeckner, Can aerosols spin down the water cycle in a warmer and moister world? Geophys. Res. Lett. 31, L06207 (2004)

24. B. Govindasamy, K. Caldeira, P.B. Duffy, Geoengineering Earth's radiation balance to mitigate climate change from a quadrupling of $\mathrm{CO}_{2}$, Global Planet. Change 37, 157 (2003)

25. K.E. Trenberth, A. Dai, Effects of Mount Pinatubo volcanic eruption on the hydrological cycle as an analog of geoengineering, Geophys. Res. Lett. 34, L15702 (2007)

26. S. Tilmes, R. Müller, R. Salawitch, The sensitivity of polar ozone depletion to proposed geoengineering schemes, Science 320, 1201 (2008)

27. D.G.Victor, M.G. Morgan, F. Apt, J. Steinbruner, K. Ricke, The geoenigeering option. A last resort against global warming, Foreign Affairs 88, 2 (2009) 